\title{
Analysis of Concrete Material through Gamma Ray Computerized Tomography
}

\author{
J. M. de Oliveira Jr. ${ }^{1,2}$, A. C. G. Martins ${ }^{2}$, and J. A. DE Milito ${ }^{2}$ \\ ${ }^{1}$ Universidade de Sorocaba - UNISO, Centro de Ciências Exatas e Tecnológicas \\ Rod. Raposo Tavares Km 92,5, Cidade Universitária, 18023-000, C.P. 578, Sorocaba, SP, Brazil \\ ${ }^{2}$ Faculdade de Engenharia de Sorocaba - FACENS \\ Rod. Senador José Ermírio de Moraes Km 1.5, 18087-090, Sorocaba, SP, Brazil
}

Received on 20 October, 2003

\begin{abstract}
Computerized Tomography (CT) refers to the cross sectional imaging of an object from both transmission or reflection data collected by illuminating the object from many different directions. The most important contribution of CT is to greatly improve abilities to distinguish regions with different gamma ray transmittance and to separate over-lying structures. The mathematical problem of the CT imaging is that of estimating an image from its projections. These projections can represent, for example, the linear attenuation coefficient of $\gamma$-rays along the path of the ray. In this work we will present some new results obtained by using tomographic techniques to analyze column samples of concrete to check the distribution of various materials and structural problems. These concrete samples were made using different proportions of stone, sand and cement. Another set of samples with different proportions of sand and cement were also used to verify the outcome from the CT analysis and the differences between them. Those samples were prepared at the Material Laboratory of Faculdade de Engenharia de Sorocaba, following the same procedures used in real case of concrete tests. The projections used in this work was obtained by Mini Computerized Tomograph of Uniso (MTCU), located at the Experimental Nuclear Physics Laboratory at University of Sorocaba. This tomograph operates with a gamma ray source of ${ }^{241} \mathrm{Am}$ (photons of $60 \mathrm{keV}$ and $100 \mathrm{mCi}$ of intensity) and a $\mathrm{NaI}(\mathrm{Tl})$ solid state detector. The system features translation and rotation scanning modes, a $100 \mathrm{~mm}$ effective field of view, and $1 \mathrm{~mm}$ spatial resolution. The image reconstruction problem is solved using Discrete Filtered Backprojection (FBP).
\end{abstract}

\section{Introduction}

Computerized Tomography (CT) imaging, as we know today, was developed to produce images of cross-sections of the human body $[1,2]$. The industrial application of CT may ultimately far exceed its medical applications. CT methods have been used in many other areas in recent years such as application in soil science [3, 4], studies of living trees to measure growth rings [5], detection of structural defects and others heterogeneities in polymer objects [6], studies of asphaltic mixture in the fatigue test analysis [7], application of gamma ray transmission in studies of water vertical ascending infiltration samples of concrete for popular habitation $[8,9]$, etc. Civil construction industry has used in recent years, non-destructive tests to evaluate concrete structure without causing any further damage to the structure. There are many tests that can be used to determine the defects in concrete: ultrasonic pulse velocity and pulse echo methods, radioactive techniques $[10,11,12,13,14]$, radar techniques and acoustic emission phenomenon. Acoustic tomography $[15,16]$ is another technique that has been used to detect defects and fissure on concrete structures. An overview on the applications of non destructive testing techniques for assessment of concrete structures is given by Baladev Raj and Jayakumar [17]. In this work will present some new results, obtained using gamma ray tomographic technique, to analyze column samples of concrete, in order to check the distribution of various materials into the concrete samples and sugest the use of this technique to determine the moisture content or concrete trace (proportion of sand and cement used in the moisture).

\section{Computerized tomography: mate- rial and methods}

The gamma ray CT miniscanner employed in this experiment [18], is a first-generation system with a fixed sourcedetector set up in which samples of concrete are translated and rotated. The data acquisition system and the movement of translation and rotation of sample are controlled by a PC. A tomographic image can be reconstructed, after a number of profiles of narrow-beam transmission are obtained at different orientations around a sample. These measurements represent the total linear attenuation coefficient of $\gamma$-rays along the path of the ray. Let $N_{i}$ denotes the number of $\gamma$-ray photons incident upon the sample within a specified time interval for a particular ray path and $N$ the corresponding number of photons exiting the sample. Then, we can write for a mono-energetic $\gamma$-ray beam: 


$$
\int \mu^{*}(x, y) d s=\ln \left(\frac{N_{i}}{N}\right)
$$

where $N_{i}$ and $N$ are Poisson variables, $\mu^{*}(x, y)$ represents the linear attenuation coefficient at $(x, y), d s$ represents the elemental distance along the ray, and the integral is along the ray path from the $\gamma$-ray source to the detector. A measurement of the incident and the exiting $\gamma$-ray gives only an integral of $\mu^{*}(x, y)$ over the ray path. The details of the sample along the ray path are summed into a single measurement. The image reconstruction problem is therefore to determine the distribution of the linear attenuation coefficient $\mu^{*}(x, y)$ through the section of the specimen crossed by each ray. This problem could be solved using two different algorithms: i) Algebraic Reconstruction Techniques (ART) [19] and ii) Discrete Filtered Backprojection (FBP) $[20,21]$. After this, the tomographic image of a cross section of the specimen studied is generated. The concrete samples utilized in this study, were made using cement type Portland-CP-II, fine natural sand, stones (coarse aggregate) with small diameter and water. The concrete blocks used in trace analysis were cilinders of approximately $10 \mathrm{~mm}$ of diameter and were subjected to uniform heating during a week, in a temperature of 100 Celsius, in order to dry the water content. The experimental set up were made with the purpose of checking defects, fissure, steel and stone distribution on concrete. Another set of samples, with different trace (proportions between sand and cement), were also used to verify if it was possible to identify the proportion of cement and sand used. The results of tomographic analyzes were obtained after a calibration of the tomographic system. Curves relating the Tomographic Units (TU) as function of linear attenuation coefficient of gamma ray as well as curves relating the trace of concrete with the gamma ray coefficient were constructed to allow the measurement of concrete physical parameters.

\section{Experimental results}

Fig. 1 shows a tomographic image of typical concrete used in civil construction, where it is possible to identify the homogeneous distribution of stones in the concrete sample. This image was displayed using a computer program named Tomografia [22].

The images showed in this paper were reconstructed using a set of projections, measured from $0^{0}$ to $180^{\circ}$ in steps of $3^{0}$ and using the FBP algorithm. These reconstructions algorithms were especially adapted to be used in the Mini Computerized Tomograph of UNISO [23]. Fig. 2 shows another tomographic image that indicates the capacity of the method to identify some structures and imperfection in concrete, such as stone and air voids.

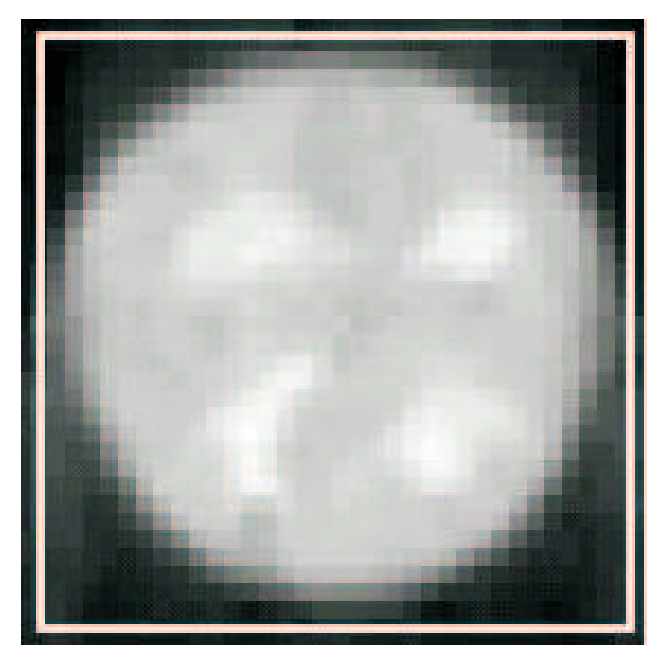

Figure 1. Tomographic image of a typical concrete sample used in Civil construction. The white regions show the stones distribution, using the FBP algorithm.

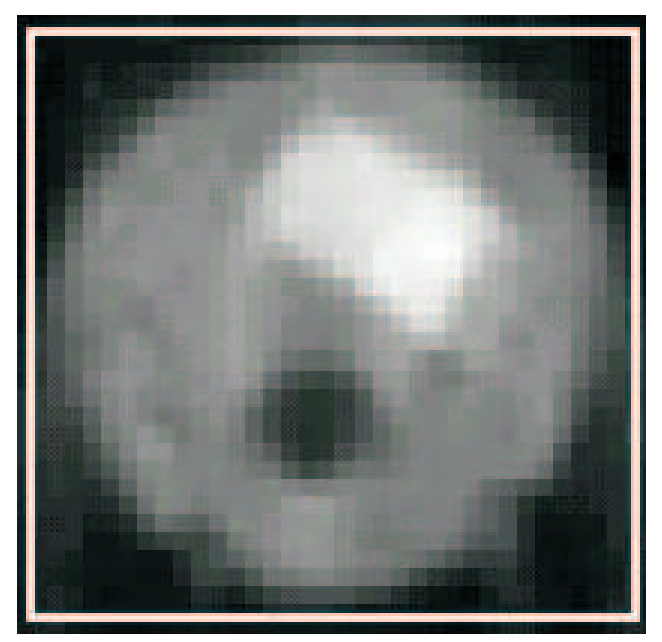

Figure 2. Tomographic image of a concrete sample showing stone(white) and one air voids(black), using the FBP algorithm.

In order to evaluate the differences between samples made with different traces, we used an experimental set up, where five samples of concrete were produced using the following mass proportions: a) only cement, b) $1: 1$, c) $3: 1$, d) 6:1 and e) 10:1 parts of sand and cement, respectively. Together with these samples, we put in the same set up, some others elements (a piece of Aluminum and a bulb of Water) to obtain the calibration curve between the intensity measured in tomographic units (TU) and linear attenuation coefficients.

Figure 3 shows the linear dependence between (TU) as a function of linear attenuation coefficient $\left(\mathrm{cm}^{-1}\right)$ of different materials, showing the ability of the tomograph to distinguish among different attenuation coefficients. 


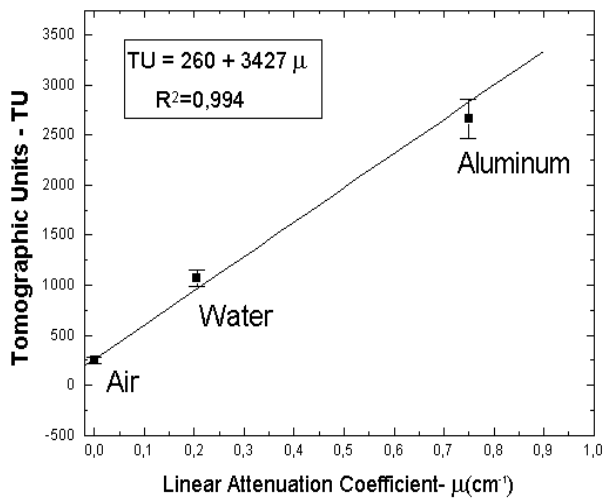

Figure 3. Calibration curve between the intensity of tomographic units (TU) and linear attenuation coefficients of air, water and aluminum.

Figs. 4 shows the dependency of the trace used in the concrete samples with the mass attenuation coefficients $\left(\mathrm{cm}^{2} / \mathrm{g}\right)$ of gamma ray into the material. The linear attenuation coefficient $\left(\mathrm{cm}^{-1}\right)$ that is proportional to the TU, is directly related to the mass attenuation coefficient through the density $\left(\mathrm{g} / \mathrm{cm}^{3}\right)$ of the material. The solid line showed in Fig. 4 is the theoretical prevision of the dependency between the trace used in the concrete with these mass coefficient. The attenuation equation for a gamma ray beam passing through the concrete, gives the relation between the mass attenuation coeficients:

$$
\mu_{t} X_{t} \rho_{t}=\mu_{c} X_{c} \rho_{c}+\mu_{s} X_{s} \rho_{s}
$$

where $\mu_{t}, \mu_{c}$ and $\mu_{s}$ are the total, cement and sand mass attenuation coefficients $\left(\mathrm{cm}^{2} / \mathrm{g}\right) ; X_{t}, X_{c}$ and $X_{s}$ are the total, cement and sand absorption thickness $(\mathrm{cm}) ; \rho_{t}, \rho_{c}$ and $\rho_{s}$ are the total, cement and sand density $\left(\mathrm{g} / \mathrm{cm}^{3}\right)$. In our analysis we are considering that $X_{t}$ can be divided in two parts, one of cement $X_{c}$ and another of sand $X_{s}$. The trace $(\mathrm{T})$ is defined by the mass rate $\left(M_{s} / M_{c}\right)$ and $\rho_{t}=\left(X_{c} \rho_{c}+X_{s} \rho_{s}\right) /\left(X_{c}+X_{s}\right)$. Thus we can relate the total mass coefficient $\left(\mu_{t}\right)$ with the trace $(T)$ by the equation:

$$
\mu_{t}=\left[\frac{(1)}{1+T}\right]\left(\mu_{c}+\mu_{s} T\right)
$$

From the measurements of the values of mass coefficient attenuation of cement and sand we can determine the dependency between the total mass coefficient and the trace. A similar dependency between the linear attenuation coefficient and the trace can be write. All analyzed samples were previously dried, thus the attenuation coefficient of water was disregarded in our equations. Fig. 4 shows a good fitting of the experimental data by theoretical prevision eq. (3).

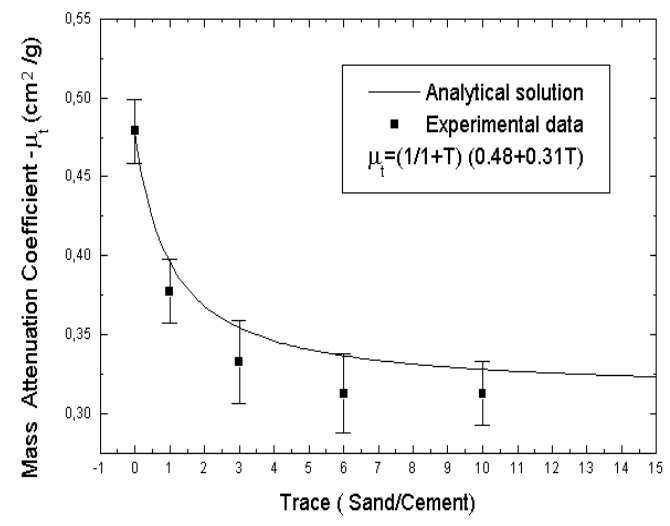

Figure 4. Solid line shows the theoretical dependency between the trace used in the concrete samples with the mass attenuation coefficients of gamma ray $\left(\mathrm{cm}^{2} / \mathrm{g}\right)$. The experimental points were obtained by tomographic techniques using the samples with the proportion between sand and cement, described in the text.

\section{Conclusion}

Although the number of concrete samples used to test the gamma ray tomographic method in our concrete analysis was small, we obtained good identification of some structures and imperfection in the concrete, such as: stone distribution, air voids and steel. The trace identification showed in Fig. 4, confirms the high potential of the method. In the case of real structure analysis, a sample must be taken and analyzed in the laboratory. We presented some possibilities of a gamma ray computerized tomography use for detail analyzis of concrete structure and the identification of concrete trace, that is a very important quantity to determine concrete quality.

\section{Acknowledgments}

The authors thank to Faculdade de Engenharia de Sorocaba - FACENS, Universidade de Sorocaba - UNISO and Fundação de Amparo a Pesquisa do Estado de São Paulo FAPESP, for the finantial suport.

\section{References}

[1] G. N. Hounsfield, British Journal of Radiology, 46, 1016 (1973).

[2] J. Ambrose, British Journal of Radiology, 46, 1023 (1973).

[3] A. M. Petrovic, J. E. Siebert, P. E. Rieke, Soil Sci. Soc. Amer. Proc. 46(3), 445 (1982).

[4] P. E. Cruvinel, R. Cesareo, S. Crestana and S. Mascarenhas, IEEE Trans. Instrum. Meas., 39(5), 745 (1990).

[5] A. M. Onoe, J. W. Tsao, H. Yamada, H. Nakamura, J. Kogure, H. Kawamura and M. Yoshimatsu, Proc. IEEE, 71(7), 907 (1983).

[6] S. Person and E. Ostman, Appl. Opt., 24(23), 4095 (1985).

[7] D. Braz, L. M. G. Motta, R. T. Lopes, Appl. Rad. and Isot., 50, 661 (1999). 
[8] M. C. Rocha, L. M. Silva, C. R. Appoloni, O. Portezan Filho, F. Lopes, L. F. Melquíades, E. A. Santos, A. O. Santos, A. C. Moreira, W. E. Pottker, E. Almeida, C. Q. Tannous, R. Y. R. Kuramoto, F. H. M. Cavalcante P. F. Barbieri, A. F. Caleffi, B. T. Carbonari, G. Carbonari, Radiation Physics and Chemistry, 61, 567 (2001).

[9] C. R. Appoloni, A. C. Nardocci, M. M. Obutti, Ciência e Cultura, 40, 387 (1987).

[10] E. M. A. Hussein and T. M. Whynot, Nucl. Instrum. Methods Phys. Res., A 283, 100 (1989).

[11] C. M. Valente, R. T. Lopes, E. F. O. Jesus, A. M. Rebello, Anais do II Encontro Nacional de Aplicações Nucleares, Caxambu, MG, 1, 145 (1993).

[12] D. Braz, R. T. Lopes, L. M. G. Motta, P. Silva, 2nd International Symposium on Maintenance and Rehabilitation of Pavements and Technological Control, Alabama (2001).

[13] E. J. Garboczi, Cement and Concrete Research, 32, 1621 (2002).

[14] L. B. Wang, J. D. Frost, G. Z. Voyiadjis, T. P. Harman, Mechanics of Materials, 35, 777 (2003).

[15] M. P. Schuller, R. H. Atkinson, Review of Progress in Quantitative Nondestructive Evaluation, 14, 2215 (1995).
[16] J. Rhazi, Y. Kharrat, G. Ballivy, M. Rivest, Inovations in nondestructive Testing of Concrete, 221 (1997).

[17] B. Raj and T. Jayakumar, Journal of Non Destructive Evaluation, 3, 29 (2001).

[18] J. M. Oliveira Jr., Brasilian Journal of Physics, 33(2), 273 (2003).

[19] R. Gordon, R. Bender and G. T. Herman, J. Theor. Biol. 29, 471 (1970).

[20] R. N. Bracewell and A. C. Riddle, Astrophys. J. 150, 427 (1967).

[21] G. N. Ramachandran and A. V. Lakshminarayanan, Proc. Nat. Acad. Sci. USA 68, 2236 (1971).

[22] L. P. C. Haak and J. M. Oliveira Jr., XXV Reunião de Trabalho Sobre Física Nuclear no Brasil, São Pedro, SP, pag. 50 (2002).

[23] J. M. Oliveira Jr., A. L. B. V. Rodrigues, C. G. Gonzales, J. L. A. Almeida, Anais do I Encontro Nacional de Física Teórica Computacional, Brasilia, DF, pag. 40 (2003). 